\title{
The Effects of Increasing Visitor and Noise Levels on Birds Within a Free-flight Aviary Examined Through Enclosure Use and Behavior
}

\author{
Mackenzie K. S. Blanchett*, Esther Finegan, and Jim Atkinson \\ Department of Animal Biosciences, University of Guelph \\ *Corresponding author (Email: mackenzie.blanchett@gmail.com)
}

Citation - Blanchett, M. K. S., Finegan, E., \& Atkinson, J. (2020). The effects of increasing visitor and noise levels on birds within a free-flight aviary examined through enclosure use and behavior. Animal Behavior and Cognition, 7(1), 49-69. doi: https://doi.org/10.26451/abc.07.01.05.2020

\begin{abstract}
Visitors in a zoo environment have the potential to impact the animals that they are viewing in a variety of ways. Recently, there have been suggestions that free-range enclosures, where visitors can walk directly through an animal's exhibit, may reduce the potential for negative visitor impacts. The aim of this study was to examine associations between visitor numbers and noise levels and enclosure use and the stress and critical behavior of 24 bird species housed in a free-flight, mixed species aviary. Using GIS (Geographic Information Systems), the locations of the birds were marked on a digital map of the aviary, with their behavior and vertical distance above the ground also marked. In addition, visitor numbers and noise levels were simultaneously monitored using scan sampling. Thirty-minute intervals were used to collect bird data, while 10-minute intervals were used to collect the visitor data. Under periods of high visitor numbers, several changes in how the birds used their enclosure space were observed, including; movement away from the visitor pathway, decreased range sizes and increased use of vegetation cover. However, the lack of association between visitor numbers and the performance of stress related (pacing, aggression), and critical behavior (feeding, resting, nesting), suggest that the birds were not experiencing substantial negative welfare consequences. Instead, the ways in which the birds used the space in their free-range enclosure appears to have minimized any potential negative effects during high visitor periods.
\end{abstract}

Keywords - Free-range enclosure, Visitor effects, Enclosure use, Behavioral responses, Mixed species aviary, GIS

The relationship between zoo animals and the visitors who view them is a complicated one, where both parties can have considerable effects on the other. The experience of visitors in zoos is often associated with feelings of happiness, relaxation, excitement, and interest in and empathy for the animals being viewed (Clayton et al., 2009; Reade \& Waran, 1996). However, without the aid of self-reporting by the zoo animals themselves, understanding the effects that visitors have on animals, can be a more complicated process. For the past 50 years, scientists have investigated the effects that human presence has on animals in captivity (Hosey, 2000). Mechanisms by which visitors can influence zoo animals include the visual presence of visitors at viewing areas, the noise that visitors create, and the attempts that visitors make to interact with the animals (Fernandez et al., 2009; Quadros et al., 2014). These components can act independently or inter-relatedly to produce negative, positive, or neutral visitor effects (Davey, 2007; Hosey, 2000, 2008, 2013). Negative visitor effects suggest that animals may find visitors to be an aversive presence, which may be due to the animals viewing visitors as a source of disturbance, a predatory or territorial threat, or a negative stimulus due to previous negative interactions 
with humans (Hosey, 2008, 2013). Alternatively, positive visitor effects suggest that visitors may be stimulating for the animals (Hosey, 2000), potentially acting as a form of social enrichment (Claxton, 2011; Hosey, 2013). Finally, neutral visitor effects have been observed where visitors appear to have no effect on the animals, suggesting animal habituation to the presence of humans in their environment, due to repeated exposure (Hosey \& Melfi, 2014).

An area of study that is beginning to receive more attention is that of visitor effects in free-range enclosures. Free-range enclosures are those in which visitors can move directly through an animal's habitat, with minimal physical barriers separating them from the animals that they are viewing (Sherwen, Hemsworth, et al., 2015). In theory, the opportunity for close-contact interactions between visitors and zoo animals, could make the animals more vulnerable to negative visitor effects (Collins et al., 2017; Morgan \& Tromborg, 2007; Woolway \& Goodenough, 2017). Increased opportunity for close-contact interactions between visitors and zoo animals has been linked to increases in the rate at which undesirable or aggressive behavior is displayed towards visitors. This has been documented in cotton-top tamarins (Saguinus oedipus, Mun et al., 2013), African pygmy goats (Capra hircus, Anderson et al., 2002) and Romanov sheep (Ovis aries, Anderson et al., 2002).

There is also evidence of increases in the performance of vigilance behavior by animals housed in free-range enclosures, as visitor numbers and noise levels increase. These responses may indicate fear and have been documented in koalas (Phascolarctos cinereus; Larsen et al. 2014) and kangaroos (Macropus fuliginosus fuliginosus and Macropus rufus; Sherwen, Hemsworth, et al., 2015). However, it has been noted that vigilance can also be an indicator of curiosity directed towards visitors (Larsen et al., 2014; Sherwen, Hemsworth, et al., 2015), resulting in uncertainty as to whether the visitor impacts are positive or negative.

Alternatively, recent studies performed on ring-tailed lemurs (Lemur catta) (Collins et al., 2017), red European squirrels (Sciurus vulgaris) (Woolway \& Goodenough, 2017) and orangutans (species name not provided) (Choo et al., 2011) housed in free-range enclosures, have reported relatively low levels of visitor effects, despite the reduced level of visitor-animal separation inherent to free-range enclosures. All three studies reported low levels of behavioral responses to increasing visitor numbers, visitor noise levels, and/or visitor distance to the animals (Choo et al., 2011; Collins et al., 2017; Woolway \& Goodenough, 2017). These limited responses to the visitors were attributed to habituation through repeated exposure, or to the animals' positive associations with humans due to their positive relationships with their keepers. Additionally, authors interpreted approach behavior or food solicitation behavior displayed by animals, as indicating a lack of fear of towards visitors (Collins et al., 2017; Woolway \& Goodenough, 2017). One study suggested that visitors may have acted as a form of enrichment by providing novel interactions and variability in the environment (Choo et al., 2011).

Furthermore, it has been proposed that design aspects of free-range enclosures may play a direct role in minimizing the effects of visitor presence on the animals housed within them (Hosey, 2000). It has been hypothesized that free-range enclosures allow for animals to remove themselves from visitor view, and distance themselves from visitors and unwanted interactions at will, providing a means by which animals may reduce the effects of visitor presence (Carlstead \& Sheperdson, 2000; Collins \& Marples, 2015; Hosey, 2000). Retreat responses such as these have been documented in free-range enclosures in lemurs (Lemur catta, Collins et al., 2017), flamingos (Phoenicopterus roseus, P. ruber, P. chilensis, Phoenicoparrus andinus, Phoeniconaias minor) (Rose et al., 2018) and squirrels (Sciurus vulgaris, Woolway \& Goodenough, 2017). In all cases, due to the design of the enclosures, the animals were able to respond to potentially stressful stimuli (visitors, large crowds, children) by moving further away from visitor pathways as preferred (Collins et al., 2017; Rose et al., 2018; Woolway \& Goodenough, 2017).

Retreat responses have been further studied through the provisioning of retreat space, areas within free-range enclosures that animals can access but visitors cannot. This has been studied in petting zoos (Anderson et al., 2002) and swim-with dolphin experiences (Kyngdon et al., 2003). These studies concluded that the ability of the animals to retreat from visitors at will allowed for the animals to maintain control over visitor interactions. This resulted in the decreased performance of 'non-desirable' behaviors directed towards visitors (Anderson et al., 2002), and the potential habituation (Kyngdon et al., 2003) to 
what might otherwise be a disruptive presence in their environment. The provisioning of choice and control for animals within their enclosures, has been shown to contribute to positive animal welfare in zoo environments (summarized in Whitham \& Wielebnowski, 2013).

Understanding how animals position themselves in free-range enclosures in response to differing visitor levels, is crucial in order to better understand the mechanisms that animals may use to potentially mitigate negative visitor effects. Combining locational data with behavior data can supply a detailed picture of visitor effects, providing a behavioral context to how the animals use their enclosures and the habitat features provided to them (de Vere, 2018). Methodology used to assess enclosure use and positioning in visitor effect studies has largely been composed of measures such as, distance from visitor pathways (Larsen et al., 2014; Sherwen, Hemsworth, et al., 2015), positions of the animals in twodimensional or three-dimensional quadrants of the enclosure (Collins et al., 2017; Collins \& Marples, 2015; de Azevedo et al., 2012; de Vere, 2018; Downes, 2012; Larsen et al., 2014; Thicks, 2008), use of retreat space (Anderson et al., 2002; Kyngdon et al., 2003) and overall visibility of the animals to visitors (Schäfer, 2014). We aim to contribute to this research further by examining the enclosure use of a community of mixed species birds housed in a free-range exhibit, through the use of digital maps and Geographic Information Systems (GIS).

GIS is a system that can be used to make digital maps, on which, data can be directly collected, stored, analysed and displayed. With GIS, the location of the birds within their enclosure can be tracked in three-dimensions, providing a highly detailed account of their locations, and how these locations change under periods of differing visitor numbers and noise levels. This information will be particularly helpful while examining visitor effects in a large free-range enclosure, whose complex naturalistic design uses features to more closely mimic a natural environment. In addition, GIS can be used to aid in easily providing information on changes in the range size of the birds, and changes in their use of features in the environment, such as vegetation cover. It is proposed that this information can aid in better understanding how the birds are using the space provided to them in their free-range enclosure, and possibly, how their positioning in the environment varies under differing visitor levels.

In the current study, enclosure use by 24 bird species was monitored during periods of differing visitor numbers and noise levels in a free-range naturalistic enclosure at Zoo Tampa at Lowry Park, FL. GIS was used to track the birds' locations on a to-scale aviary map. It was hypothesized that under periods of increased visitor numbers/noise levels birds would: (1) be found further away from the path; (2) be found higher up in the canopy; (3) be found more often in ground vegetation cover, and/or; (4) display smaller range sizes. In addition, it was hypothesized that any associated negative welfare of the birds during periods of increased visitor numbers or noise levels would be seen through changes in their behavior, including increased performance of stress related behaviors, such as pacing and/or aggression, and decreased performance of critical behavior, such as feeding, nesting and resting.

\section{Methods}

\section{Subjects}

The study was conducted at Zoo Tampa at Lowry Park, Florida (United States). The aviary of focus was the Main Free-flight Aviary: a large, naturalistic, free-range enclosure (Figure 1). The aviary is an outdoor, dome-shaped enclosure (approximately $34 \times 28 \mathrm{~m}$ across and $13.5 \mathrm{~m}$ high) surrounded by wire mesh, that allows full exposure for the birds to the outside weather conditions. In addition, the naturalistic design incorporates abundant ground vegetation cover and trees, a running waterfall, and a river and pond. A cement path near the edges of the habitat (Figure 1) allows visitors to walk through the aviary encountering the birds in close proximity with no physical barriers, while prohibiting visitor movement into the center and surrounding edges of the enclosure with a low-rope fence. In the center of the aviary, there is a raised viewing platform and stairs, on which visitors can gain an elevated view of the birds, approximately four meters above the ground. However, the platform was closed to visitors for repairs throughout the study period. 
Blanchett et al. 52

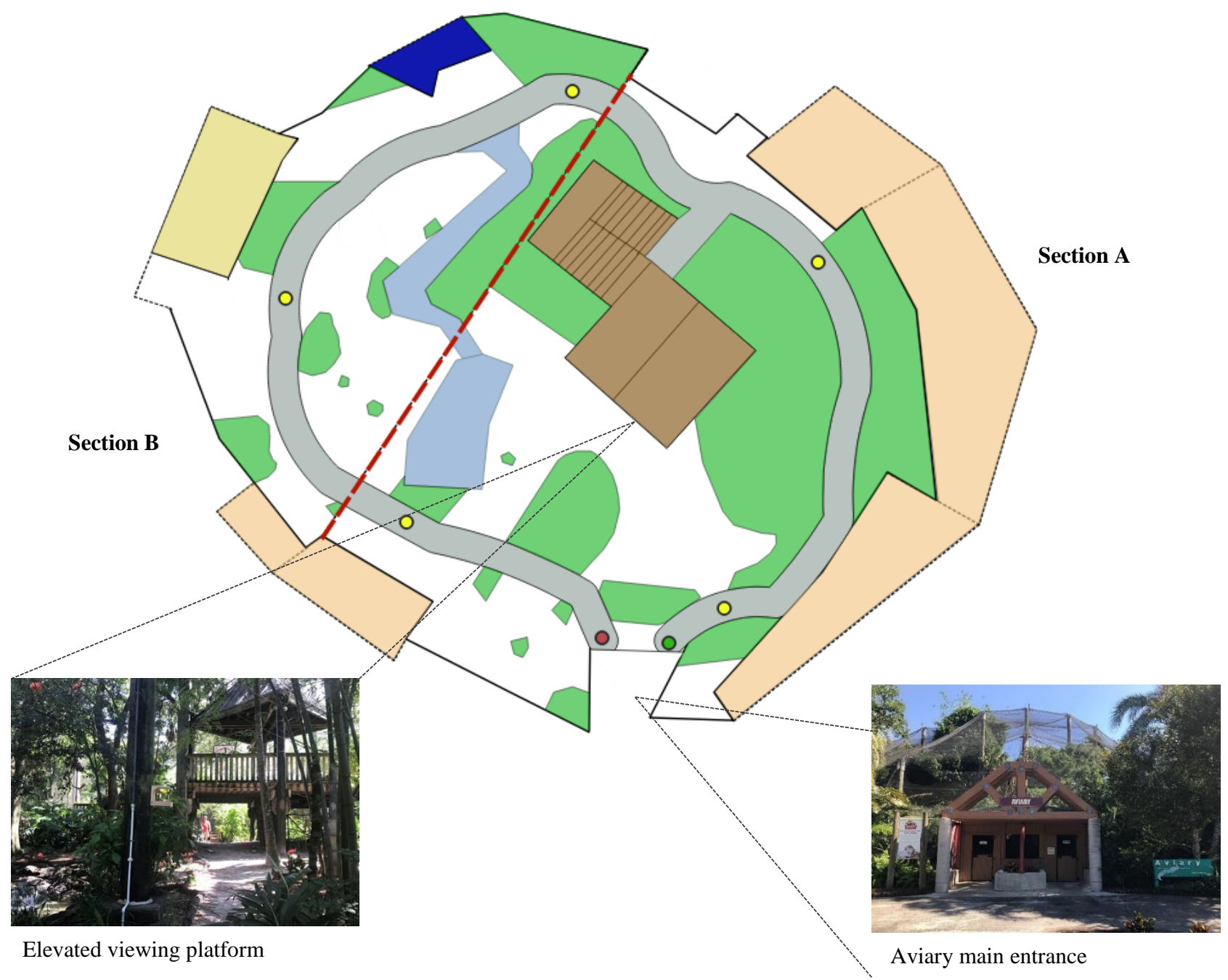

\begin{tabular}{|c|c|c|}
\hline \multicolumn{3}{|c|}{ Legend } \\
\hline 0 & Entrance & Viewing platform and stairs (closed for \\
\hline O & Exit & duration of observation period) \\
\hline 0 & Noise reading locations & Keeper offices \\
\hline & Visitor pathway & External contained aviaries \\
\hline & Pond and river & Ground vegetation cover \\
\hline & Waterfall & Wire mesh wall dividing sections $\mathrm{A}$ and $\mathrm{B}$ \\
\hline
\end{tabular}

Figure 1. An overhead map of the Main Free-flight Aviary at Zoo Tampa at Lowry Park, Tampa FL, used for data collection, analysis and interpretation. 
At the time of this study, the aviary was home to 26 bird species and two Linnaeus's two-toed sloths (Choloepus didactylus), of which 24 bird species (98 individual birds) were included in the data collection (Table 1; see Appendix for photographs). Two species, the crested oropendola (Psarocolius decumanus) and the nicobar pigeon (Caloenas nicobarica), were omitted from analysis, as it was determined during two days of pre-study data collection, that their high levels of activity made it too difficult to ensure that individuals of either population were not sampled more than once within the same scan period. The aviary was divided into two sections, section A and B. The two sections were separated by a wire mesh wall with chain curtains that visitors could pass through. This division allowed for the separation of species, as well as two related scarlet ibis populations. However, it is of note that some species could pass through the curtains, accessing both sides of the aviary at will (Table 1). In addition, there were several traditional bird exhibits along the edges of the aviary (Figure 1, external contained aviaries) that visitors could view once inside, but could not enter, and as such, these birds were not included in the study.

Table 1

An Inventory of the Main Free-flight Aviary at Zoo Tampa at Lowry Park, Tampa, FL

\begin{tabular}{|c|c|}
\hline Species & Sex* \\
\hline \multicolumn{2}{|l|}{ Section A } \\
\hline African openbill (Anastomus lamelligerus) ${ }^{* * *}$ & 2:0:0 \\
\hline African spoonbill (Platalea alba) & $1: 1: 0$ \\
\hline Black-bellied whistling duck (Dendrocygna autumnalis) ${ }^{* *}$ & $2: 2: 4$ \\
\hline Blue-crowned motmot (Momotus coeruliceps) & $1: 1: 0$ \\
\hline Boat-billed heron (Cochlearius cochlearius) & $4: 1: 0$ \\
\hline Buff-banded rail (Hypotaenidia philippensis) ${ }^{* *}$ & $1: 0: 1$ \\
\hline Demoiselle crane (Anthropoides virgo) & $1: 1: 0$ \\
\hline Great curassow (Crax rubra) & 1:0:0 \\
\hline Helmeted guineafowl (Numida meleagris) & $1: 1: 3$ \\
\hline Hottentot teal (Spatula hottentota) ${ }^{* *}$ & 2:0:0 \\
\hline Mandarin duck (Aix galericulata)** & $1: 1: 0$ \\
\hline Pied imperial pigeon (Ducula bicolor) & $1: 1: 0$ \\
\hline $\begin{array}{l}\text { Sacred ibis (Threskiornis aethiopicus) } \\
\text { Scarlet ibis (Eudocimus ruber) }\end{array}$ & $\begin{array}{c}2: 0: 0 \\
16: 17: 6\end{array}$ \\
\hline $\begin{array}{l}\text { Spotted whistling duck (Dendrocygna guttata) }{ }^{* *} \\
\text { Sunbittern (Eurypyga helias)** }\end{array}$ & $\begin{array}{l}2: 0: 0 \\
3: 0: 0\end{array}$ \\
\hline Von der Decken's hornbill (Tockus deckeni)** & $0: 1: 0$ \\
\hline \multicolumn{2}{|l|}{ Section B } \\
\hline Blue-bellied roller (Coracias cyanogaster) & 1:0:0 \\
\hline Blue-breasted kingfisher (Halcyon malimbica) & $0: 1: 0$ \\
\hline Eastern crested guineafowl (Guttera pucherani) & 0:1:0 \\
\hline Inca tern (Larosterna inca) & $2: 3: 0$ \\
\hline Little blue heron (Egretta caerulea) & 0:1:0 \\
\hline Red-legged seriema (Cariama cristata) & $1: 1: 0$ \\
\hline Scarlet ibis (Eudocimus ruber) & 2:1:0 \\
\hline Violet turaco (Musophaga violacea) & $1: 1: 0$ \\
\hline
\end{tabular}




\section{Production of Aviary Map in GIS}

To survey the aviary, traversing (Wenger, 1984) was used. The entrance to the aviary was selected as the known point $(0,0)$, from which the distance (measured with a TruPulse Laser Rangefinder Series 200; Laser Technology Inc., Centennial, CO, USA) and the angle of degrees north (measured with the Compass App on iPhone 6S; Apple Canada Inc., Toronto, ON, Canada) to subsequent points were measured and recorded. Key points along features such as the path, river, pond, waterfall, vegetation cover and interior walls of the aviary were measured. Once completed, the distance and angle recordings were input into Microsoft Excel 2013 (Microsoft Corporation, Redmond, WA, USA) and converted to positions in a plane coordinate system. These positions were uploaded to a blank georeferenced surface in QGIS Desktop 2.18.3 with GRASS 7.2.0 (open-source software product) as delimited text files with point coordinates. Aviary features were digitized from these point coordinates as lines, shapes or point files as appropriate (Figure 1).

\section{Observational Data Collection Procedures}

Bird data. Data collection occurred from June 12, 2017 to July 7, 2017. Data for 12 full days was collected, with sampling occurring from 9:00am - 1:00pm and 2:00pm - 4:00pm, on both weekend and weekdays. Scan sampling (Martin \& Bateson, 2007) was used to collect location and behavior data of the birds. Two days of pre-study sampling were conducted before the study began, during which time it was determined that it would take approximately $20 \mathrm{~min}$ to sight and record all of the subject birds in the aviary. To ensure adequate time for data collection, as well as allow for time to reset before the subsequent sampling period, a $30 \mathrm{~min}$ interval was allocated for each scan. At the beginning of every 30 min interval, the observer walked through the enclosure, along the pathway, marking the location of each sighted bird on a hardcopy version of the aviary map. In addition, the species of bird, the behavior the bird was performing (Table 2), the vertical distance of the bird above the ground (measured using the TruPulse Laser Rangefinder Series 200), and the date and time of sampling were recorded in association with each bird's locational point on the map. Due to the inability to distinguish individual birds, and the scale of the map on which data was being collected, when more than three birds (of any species) were located in a grouping within the same relative area of space (approximately $0.5 \mathrm{~m}^{3}$ ), vertical distance above the ground was recorded as a group measure. Instead of measuring the distance above the ground for every bird within the grouping, vertical distance would be measured for a bird located in approximately the center of the group, and this distance measure would be applied to all of the birds within that group. In addition, for these groupings, a note was made of how many birds of each species were performing each behavior (e.g., six scarlet ibis feeding and drinking, two scarlet ibis resting, one sacred ibis pacing). These behaviors were then assigned at random to the locational points within a grouping, according to species (see Data Entry into GIS).

To minimize the likelihood that individual birds of the same species were recorded more than once in the same scan, to the best of the observer's ability, individuals of the same species were recorded when all individuals of the given species were in-sight. Additionally, for the majority of the bird species, there were populations of one or two individuals, and in these cases, it was possible to keep track of how many individuals had already been sampled. However, as observers cannot fully guarantee that individual birds were not double-counted during scans, it must be noted that this paper serves to provide a sampling of each population's use of the enclosure and behavior.

Visitor and environmental data. Using 10 min scan sampling, a second observer simultaneously recorded visitor and environmental variables. To maximize the detail and accuracy of air temperature and humidity readings, visitor and environmental data were collected at $10 \mathrm{~min}$ sampling intervals, coordinated with the start of bird sampling intervals (e.g., bird sampling periods began at 9:00, 9:30, 10:00, etc. and visitor and environmental sampling periods began at 9:00, 9:10, 9:20, 9:30, etc.). The total number of visitors who entered the aviary during the ten-minute sampling period was recorded. As well, noise readings from five points along the pathway (Figure 1; measured using a Dr. Meter MS10 Digital 
Decibel Sound Level Meter Tester; Hisgadjet, Union City, CA, USA) along with air temperature and humidity measured at the entrance of the aviary (both measured using the Kestrel 4000; NielsenKellerman, Boothwyn, PA, USA), were recorded at the beginning of each 10 min sampling period. Due to the nature of the live observations, intra-observer reliability could not be collected for the bird, visitor or environmental data.

Table 2

An Ethogram of Bird Behavior Recorded Throughout the Study

\begin{tabular}{ll}
\hline \multicolumn{1}{c}{ Behavior } & \multicolumn{1}{c}{ Description } \\
\hline Critical Behavior* & Sitting, perching, or standing on land, structures or in the water, with eyes closed \\
\hline Resting & Gathering, washing or consuming food, or drinking water \\
Feeding and Drinking & Sitting on nest or nesting structure \\
Nesting & \\
\hline Stress-related Behavior** & Walking back and forth in a set route with no apparent goal \\
\hline Pacing & Chasing, biting or vocalizing aggressively (e.g., hissing) at other birds \\
\hline Agonistic Interactions & Ched
\end{tabular}

Note: Behaviors to include were determined based on those that were observed in preliminary trial-runs of data collection.

* denotes behaviors categorized as critical behaviors for the purposes of this study: if birds show a reduction in these behaviors, this may indicate long-term welfare consequences for the bird concerning their health or their ability to perform natural behaviors ** denotes behaviors categorized as stress related behaviors for the purposes of this study: if birds show an increase in these behaviors, this may indicate the birds are experiencing increased stress levels

\section{Statistical Analyses}

To aid in ensuring that each species was accurately and sufficiently sampled, species that were not successfully sighted and recorded in at least 70 percent of the total scans were excluded from the formal results. Only two species (the pied imperial pigeon [Ducula bicolor] and blue-crowned motmot [Momotus coeruliceps]) did not meet the cut-off of successfully being found in at least 70 percent of scans; all other species were included in the formal analysis. In addition, due to the lack of variability in environmental conditions recorded throughout the study (air temperature levels ranged from $26.7^{\circ} \mathrm{C}$ to $34.2^{\circ} \mathrm{C}$ per half hr scan, and humidity levels ranged from $19.0 \mathrm{~g} / \mathrm{m}^{3}$ to $26.1 \mathrm{~g} / \mathrm{m}^{3}$ per half $\mathrm{hr}$ scan), air temperature and humidity levels were not included in the formal analysis.

Data entry into GIS. A total of 132 scans were recorded over the 12 day period, with 11,115 bird observations in total. For each observation, the location of the bird in the enclosure was digitized onto the digital aviary map in QGIS along with the corresponding bird, visitor and environmental attribute data (Table 3). Visitor and environmental data were linked to bird data using date and time of sampling period. Total visitor numbers for each $30 \mathrm{~min}$ period were calculated by summing the visitor totals for the three corresponding $10 \mathrm{~min}$ scans. Average noise levels for each $30 \mathrm{~min}$ period were calculated by averaging the noise levels for the three corresponding $10 \mathrm{~min}$ scans (Table 3 ). To determine each bird's distance from the path for each scan, a 'nearest neighbor join' that calculated the distance in meters from each data point to the nearest part of the path, was performed in QGIS and added as an additional attribute (Table 3). To map the locations in three-dimensions, points were converted to ' $\mathrm{Z}$ points' using the vertical distance of the bird from the ground as the $\mathrm{Z}$ coordinate. Presence of the birds in ground vegetation cover ('vegetation use') was added as an attribute by digitizing the locations of heavy ground vegetation onto the map. A 'select by location' was run on birds with a vertical distance of zero against the ground vegetation cover layer (Table 3). 
Table 3

Attribute Data Recorded During Observations and Input into GIS

\begin{tabular}{|c|c|}
\hline Attribute & Description \\
\hline Date & Date that the data point was recorded \\
\hline Time & $\begin{array}{l}\text { Time at the beginning of the } 30 \text { min scan sampling period during which the data point was recorded } \\
\text { (e.g., 9:00; 9:30, 10:00, etc.) }\end{array}$ \\
\hline $\begin{array}{l}(\mathbf{X}, \mathbf{Y}, \mathbf{Z}) \\
\text { Coordinates }\end{array}$ & $\begin{array}{l}\mathrm{X} \text { and } \mathrm{Y} \text { coordinates automatically calculated from the location of the data point on the digital, to-scale, } \\
\text { aviary map in QGIS. Z Coordinate calculated from the vertical height of the birds from the ground }\end{array}$ \\
\hline Vertical Height & Vertical height of the bird above the ground (m) \\
\hline Species & Species of the bird (Table 1) \\
\hline Behavior & Behavior being performed by the bird (Table 2) \\
\hline Number of visitors & $\begin{array}{l}\text { The total number of visitors who entered the aviary (including the two observers) during the } \\
\text { corresponding } 30 \text {-min scan period (measured at } 10 \text { min scan sample intervals and summed per half hr } \\
\text { period) }\end{array}$ \\
\hline Noise Level & $\begin{array}{l}\text { Average noise level }(\mathrm{dBa}) \text { recorded within the aviary during the corresponding } 30 \text { min scan period } \\
\text { (measured at ten-minute scan sample intervals and averaged per half hr period) }\end{array}$ \\
\hline Vegetation Use & Is the bird in an area of ground level vegetation cover? $(1=\mathrm{Yes}, 0=\mathrm{No})$ \\
\hline $\begin{array}{l}\text { Distance from the } \\
\text { Path }\end{array}$ & $\begin{array}{l}\text { Distance of the bird from the visitor pathway }(\mathrm{m}) \text { as calculated using the 'nearest neighbour join' } \\
\text { function in QGIS }\end{array}$ \\
\hline
\end{tabular}

Spearman's correlation coefficients: Comparisons of the birds' location in the aviary to visitor variables. To determine how visitor numbers and noise levels were correlated with the birds' horizontal distance from the path and vertical distance from the ground, Spearman's Correlation Coefficients were calculated using SAS software (University Edition version SAS Studio 3.6 and SAS 9.4M4; SAS Institute Inc., Cary, NC, USA). Spearman's correlation coefficients were used to account for the non-normal distribution of the variables. Correlations were calculated between the birds' horizontal distance from the path against; (1) the total number of visitors who entered the aviary during the corresponding scan period, and; (2) the average noise level in the aviary during the corresponding scan period. As well, correlations were calculated between the birds' vertical distance above the ground against; (1) the total number of visitors who entered the aviary during the corresponding scan period, and; (2) the average noise level in the aviary during the corresponding scan period. Bonferroni corrections were applied to account for the number of correlations run. Thus, a $p$-value of $.0125(0.05 / 4)$ was used to determine significance.

Chi-square test: Comparisons of the birds' ground vegetation use to visitor numbers. To determine how the birds' presence in ground vegetation cover was associated with differing levels of visitor numbers, a Chi-square test was run using SAS Software at a significance level of $\alpha=0.05$. A Chisquare test was run comparing the number of scans in which birds were found in ground vegetation cover in periods of low visitor numbers (classified as half hr scans in which two to 60 visitors entered the aviary, $n=63$ ) and the number of scans in which birds were found in ground vegetation cover in periods of high visitor numbers (classified as scans in which 61 to 189 visitors entered the aviary, $n=69$ ), with the null hypothesis that there would be no association between the number of scans in which birds were observed in ground vegetation cover and the visitor condition. A Fisher's Exact test was run to analyze 
the probability that vegetation use of birds in periods of high visitor numbers exceeds the probability of vegetation use by birds in periods of low visitor numbers. Due to the nature of the observational study design, there was an imbalance in sample sizes between scans that took place during low noise levels (classified as scans in which noise levels ranged from $51.5 \mathrm{dBa}$ to $61.5 \mathrm{dBa}, n=115$ scans) and scans that took place during high noise levels (classified as scans in which noise levels ranged from $61.6 \mathrm{dBa}$ to $66.6 \mathrm{dBa}, n=17$ scans). As such, the results of the Chi-square test for noise level comparisons were statistically insignificant and not included in the formal results.

Three-dimensional matrix: Range size comparisons. To assess changes in range size under periods of differing visitor numbers, species' range sizes were estimated and compared under periods of low visitor numbers and periods of high visitor numbers (described above). Python (Python Version 2.7; Python Software Foundation; Wilmington, DE, USA) was used to break the study area into a series of three-dimensional $1 \mathrm{~m}^{3}$ grid cells. To determine which species were observed in each cell, the $\mathrm{X}, \mathrm{Y}, \mathrm{Z}$ coordinates for each bird's locational data point were collected in QGIS and overlaid on the grid cells. To determine each species' range size, counts of how many cells each species occupied under periods of low visitor numbers and counts of how many cells each species occupied under periods of high visitor numbers were performed. Number of cells occupied was then converted into range size estimates in cubic meters. Percentage change in range size for each species, from periods of low visitor numbers to periods of high visitor numbers, were calculated using these totals. Due to the small number of scans that took place during periods of high noise levels, a representative sampling of species' ranges during periods of high noise levels could not be completed, and as such, the data did not allow for effective range comparisons between periods of low noise levels and periods of high noise levels.

Chi-square test: Behavior data comparisons. To determine how bird behavior was associated with differing levels of visitor numbers, a Chi-square test was run using SAS Software at a significance level of $\alpha=.05$. Scans were categorized as either periods of high visitor numbers or periods of low visitor numbers (as described previously). Pooling all of the species data, we counted the number of times each stress related behavior (aggression, pacing) and each critical behavior (nesting, resting, and feeding and drinking) were observed during periods of high visitor numbers and the number of times stress related behavior and critical behavior were observed during periods of low visitor numbers. A Chi-square test was run to compare the total count for each behavior type in periods of high visitor number and the total count for each behavior type in periods of low visitor numbers, with the null hypothesis that there would be no association between frequency of behavior observed and the visitor condition. Due to small sample size, behavior data were pooled across species. Again, due to the imbalance in sample sizes between scans that took place during low noise levels and scans that took place during high noise levels, the results of the Chi-square test for noise level comparisons were statistically insignificant, and as such, not included in the formal results.

\section{Results}

\section{Summary of Aviary Conditions}

Visitor numbers and noise levels fluctuated throughout the study. Visitor numbers ranged from two to 189 guests per half hour scan $(M=68$ guests) and noise level readings ranged from $51.5 \mathrm{dBa}$ to $66.6 \mathrm{dBa}$ per half hour scan period $(M=59.0 \mathrm{dBa})$, equating to, approximately, what would be perceived by humans as a two-fold increase in noise levels. From general observations of the aviary, it was noted that visitors tended to move steadily through the aviary, spending two to three minutes walking along the path. Most commonly, guests stopped at the kookaburra cage, the waterfall and the pond. Guest flow was relatively steady, with large camp groups of children coming through sporadically throughout the day, and visitor numbers increasing around 10:00am, and decreasing after 1:00pm. Calculation of correlation coefficients showed that noise levels and visitor levels were moderately correlated $(N=132, r=.366, p<$ $.001)$. 


\section{Comparisons of the Birds' Location in the Aviary to Visitor Variables}

Three species of birds displayed changes in distance from the visitor pathway as visitor numbers and noise levels increased (Table 4). Two species showed a weak positive relationship between horizontal distance from the path and visitor numbers. The helmeted guineafowl $\left(N=563, r_{s}=.243, p<.001\right)$ and the hottentot teal $\left(N=228, r_{s}=.218, p=.001\right)$ were both found further away from the visitor path as visitor numbers increased. In addition, both species and the demoiselle crane showed a weak positive relationship between horizontal distance from the path and noise levels. The demoiselle crane $\left(N=263, r_{s}\right.$ $=.174, p=.005)$, the helmeted guineafowl $\left(N=563, r_{\mathrm{s}}=.222, p<.001\right)$ and the hottnetot teal $(N=228$, $\left.r_{s}=.165, p=.126\right)$ were all found further away from the visitor pathway as noise levels increased. No species showed a significant relationship between vertical distance from the ground and visitor numbers or noise levels. In addition, visitor numbers and noise levels were positively correlated for the demoiselle crane $\left(N=263, r_{s}=.359, p<.001\right)$, helmeted guineafowl $\left(N=563, r_{s}=.401, p<.001\right)$ and hottentot teal $\left(N=228, r_{s}=.368, p<.001\right)$.

Table 4

Correlations between Birds' Horizontal Distance from the Path and Vertical Distance from the Ground against Visitor Numbers and Noise Levels.

A) Demoiselle crane (Anthropoides virgo) $(N=263)$

\begin{tabular}{lcccc}
\hline & Horizontal Distance & Vertical Distance & Visitor Numbers & Noise Levels \\
\hline Horizontal Distance & - & - & - & - \\
Vertical Distance & $r_{s}=-.002$ & - & - & - \\
& $p=.969$ & & - & - \\
Visitor Numbers & $r_{s}=-.690$ & $r_{s}=-.016$ & \\
Noise Levels & $p=.265$ & $p=.798$ & $\boldsymbol{r}_{s}=. \mathbf{3 5 9}$ & - \\
& $\boldsymbol{r}_{s}=\mathbf{. 1 7 4}$ & $r_{s}=.034$ & $\boldsymbol{p}<.001$ &
\end{tabular}

B) Helmeted guineafowl (Numida meleagris) $(N=\mathbf{5 6 3})$

\begin{tabular}{lcccc}
\hline & Horizontal Distance & Vertical Distance & Visitor Numbers & Noise Levels \\
\hline Horizontal Distance & - & - & - & - \\
Vertical Distance & $r_{s}=-.117$ & - & - & - \\
& $p=.079$ & & - & - \\
Visitor Numbers & $\boldsymbol{r}_{s}=.243$ & $r_{s}=-.024$ & & - \\
Noise Levels & $\boldsymbol{p}<.000$ & $p=.720$ & $\boldsymbol{r}_{s}=. \mathbf{4 0 1}$ & $\boldsymbol{p}<.001$
\end{tabular}

C) Hottentot teal (Spatula hottentota) $(N=228)$

\begin{tabular}{|c|c|c|c|c|}
\hline 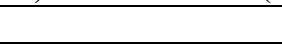 & Horizontal Distance & Vertical Distance & Visitor Numbers & Noise Levels \\
\hline Horizontal Distance & - & - & - & - \\
\hline Vertical Distance & $\begin{aligned} r_{s} & =.074 \\
p & =.085\end{aligned}$ & - & - & - \\
\hline Visitor Numbers & $\begin{aligned} r_{s} & =.218 \\
p & =.001\end{aligned}$ & $\begin{aligned} r_{s} & =.080 \\
p & =.058\end{aligned}$ & - & - \\
\hline Noise Levels & $\begin{aligned} r_{s} & =.165 \\
p & =.013\end{aligned}$ & $\begin{aligned} r_{s} & =.066 \\
p & =.119\end{aligned}$ & $\begin{aligned} r_{s} & =.368 \\
p & <.001\end{aligned}$ & - \\
\hline
\end{tabular}

Note. Species that displayed significant results for the Spearman's Correlation Coefficient test examining associations between birds' horizontal distance from the path and vertical distance from the ground, against; (1) number of visitors within the aviary during the scan period, and; (2) noise levels within the aviary during the scan period. Bonferroni corrections were applied so that significance was determined at $\alpha=.0125$. Significant correlations denoted in bold. 


\section{Comparisons of the Birds' Ground Vegetation Use to Visitor Numbers}

For three species, there was a significant association between frequency of observed use of ground vegetation cover and visitor condition (periods of low vs. high visitor numbers) (Table 5). The hottentot teal $\left(\chi^{2}(1, N=111)=4.045, p=.044\right.$ and the sunbittern $\left(\chi^{2}(1, N=55)=9.539, p=.002\right)$ were both observed in vegetation cover more frequently during periods of high visitor numbers than periods of low visitor numbers. Alternatively, the demoiselle crane $\left(\chi^{2}(1, N=26)=7.323, p=.007\right)$ were observed in vegetation cover less frequently during periods of high visitor numbers than periods of low visitor numbers. For the hottentot teal $(p=.030)$ and sunbittern $(p=.001)$ the probability of the birds being found in vegetation cover in periods of high visitor numbers exceeded the probability of the birds being found in vegetation cover in periods of low visitor numbers. For the demoiselle crane the probability of the birds being found in vegetation cover in periods of low visitor numbers exceeded the probability of the birds being found in vegetation cover in periods of high visitor numbers $(p=.998)$.

Table 5

Association between Vegetation Use and Level of Visitor Numbers

\begin{tabular}{|c|c|c|c|c|}
\hline Species & $\begin{array}{l}\text { Overall } \\
\text { sample }\end{array}$ & $\begin{array}{l}\text { Number of scans in which } \\
\text { birds were present in ground } \\
\text { vegetation cover in low } \\
\text { visitor periods }\end{array}$ & $\begin{array}{l}\text { Number of scans in which } \\
\text { birds were present in ground } \\
\text { vegetation cover in high } \\
\text { visitor periods }\end{array}$ & $\begin{array}{l}\text { Chi square test of } \\
\text { independence }\end{array}$ \\
\hline $\begin{array}{l}\text { Demoiselle crane } \\
\text { (Anthropoides } \\
\text { virgo) }\end{array}$ & 26 & 19 & 7 & $\begin{array}{c}X^{2}=7.323 \\
p=.007 \\
d f=1\end{array}$ \\
\hline $\begin{array}{l}\text { Hottentot teal } \\
\text { (Spatula hottentota) }\end{array}$ & 111 & 45 & 66 & $\begin{array}{c}X^{2}=4.045 \\
p=.044 \\
d f=1\end{array}$ \\
\hline $\begin{array}{l}\text { Sunbittern } \\
\text { (Eurypyga helias) }\end{array}$ & 55 & 15 & 40 & $\begin{array}{c}X^{2}=9.539 \\
p=.002 \\
d f=1\end{array}$ \\
\hline
\end{tabular}

Note. Species that displayed significant results for the Chi-square test examining the association between the birds' use of ground vegetation cover and the visitor condition (scans with low visitor numbers [two to 60 visitors per half hr scan], scans with high visitor numbers [61 to 189 visitors per half hour scan]). Significance determined at $\alpha=0.05$.

\section{Changes in Range Size}

Several species displayed differences in range size between periods of low and high visitor periods (Table 6). Decreases in range size of at least 10 percent from periods of low visitor numbers to periods of high visitor numbers, were seen in the African openbill (range decrease $=-13.95, n_{\text {low }}=53$, $n_{\text {high }}=63$ ), blue breasted kingfisher (range decrease $=-22.73$ percent, $n_{\text {low }}=53, n_{\text {high }}=56$ ), great curassow (range decrease $=-21.43$ percent, $n_{\text {low }}=57, n_{\text {high }}=64$ ), hottentot teal (range decrease $=-20.59$ percent, $n_{\text {low }}=59, n_{\text {high }}=64$ ), and the scarlet ibis population in section A of the aviary (range decrease $=-12.68$ percent, $n_{\text {low }}=63, n_{\text {high }}=69$ ). Alternatively, increases in range sizes of at least 10 percent from periods of low visitor numbers to periods of high visitor numbers, were seen in the blue-belied roller (range increase $=18.8$ percent, $n_{\text {low }}=59, n_{\text {high }}=62$ ), eastern crested guineafowl (range increase $=10.53$ percent, $n_{\text {low }}=63$, $n_{\text {high }}=68$ ), little blue heron (range increase $=27.27$ percent, $n_{\text {low }}=57, n_{\text {high }}=62$ ), sacred ibis (range increase $=15.78$ percent, $\left.n_{\text {low }}=62, n_{\text {high }}=69\right)$ and Von der Decken's hornbill (range increase $=18.42$ percent, $n_{\text {low }}=42, n_{\text {high }}=56$ ). 
Table 6

Changes in Range Size Under Periods of High Visitor Numbers

\begin{tabular}{|c|c|}
\hline Species & $\begin{array}{c}\text { Change in range size under periods } \\
\text { of high visitor numbers } \\
\text { (\% increase/decrease })\end{array}$ \\
\hline \multicolumn{2}{|l|}{ Section A } \\
\hline African openbill (Anastomus lamelligerus) & -13.95 \\
\hline African spoonbill (Platalea alba) & -6.78 \\
\hline Black-bellied whistling duck & -5.71 \\
\hline \multicolumn{2}{|l|}{ (Dendrocygna autumnalis) $* *$} \\
\hline Boat-billed heron (Cochlearius cochlearius) & 7.02 \\
\hline Buff-banded rail (Hypotaenidia philippensis) ${ }^{* *}$ & -2.70 \\
\hline Demoiselle crane (Anthropoides virgo) & -4.62 \\
\hline Great curassow (Crax rubra) & -21.43 \\
\hline Helmeted guineafowl (Numida meleagris) & 1.90 \\
\hline Hottentot teal (Spatula hottentota) ${ }^{* *}$ & -20.59 \\
\hline Mandarin duck (Aix galericulata) ${ }^{* *}$ & -3.39 \\
\hline Sacred ibis (Threskiornis aethiopicus) & 15.78 \\
\hline Scarlet ibis (Eudocimus ruber) & -12.68 \\
\hline Spotted whistling duck (Dendrocygna guttata)** & 2.86 \\
\hline Sunbittern (Eurypyga helias) ${ }^{* *}$ & -3.03 \\
\hline Von der Decken's hornbill (Tockus deckeni)** & 18.42 \\
\hline \multicolumn{2}{|l|}{ Section B } \\
\hline Blue-bellied roller (Coracias cyanogaster) & 18.18 \\
\hline Blue-breasted kingfisher (Halcyon malimbica) & -22.73 \\
\hline Eastern crested guineafowl (Guttera pucherani) & 10.53 \\
\hline Inca tern (Larosterna inca) & -6.94 \\
\hline Little blue heron (Egretta caerulea) & 27.27 \\
\hline Red-legged seriema (Cariama cristata) & 3.23 \\
\hline Scarlet ibis (Eudocimus ruber) & 6.52 \\
\hline Violet turaco (Musophaga violacea) & 0.00 \\
\hline
\end{tabular}

\section{Behavior Data Comparisons}

There was no significant association observed between behavior counts (stress related behavior [aggression, pacing] and critical behavior [nesting, resting, and feeding and drinking]) and visitor condition (periods of low vs. high visitor numbers) $\left(\chi^{2}(4, N=2357), p=.075\right)$.

\section{Discussion}

\section{Changes in Enclosure Use as Visitor Numbers and Noise Levels Increase}

Several changes in enclosure use were seen across the 24 bird species under periods of increased visitor numbers and noise levels (Table 4). Movement away from the visitor pathway as visitor presence within the aviary increased was seen in three species (demoiselle crane, helmeted guineafowl, and hottentot teal). Distance of animals from visitor viewing areas has been used as a measure of visitor impact in many previous studies (Bonnie et al., 2016; Larsen et al., 2014; Sherwen, Harvey, et al., 2015; Sherwen, Hemsworth, et al., 2015; Sherwen, Magrath, Butler, \& Hemsworth, 2015; Sherwen et al., 2014). It has been proposed that animals that move further away from viewing areas as visitor presence increases, may perceive visitors as a potentially fear-provoking or disruptive stimulus, from which the 
animals are actively distancing themselves (Sherwen, Harvey, et al. 2015; Sherwen, Magrath, Butler, et al., 2015). Thus, these may be responses of the birds that could indicate that they are actively distancing themselves from some aspect of increasing visitor levels that they find disruptive.

It is interesting to note all of the birds that distanced themselves from the visitor pathway were species that spent the majority, or all, of their time at ground level. As well, vertical distance above the ground did not appear to be influenced by visitor numbers or noise levels. This suggests that the ability of birds to position themselves above, or distance themselves from, visitors on a vertical scale, may play a role in reducing the likelihood that birds will respond to increases in visitor presence. This agrees with the results of a similar study examining orangutans housed in two different free-range enclosures (Choo et al., 2011). When the orangutans were housed in an enclosure elevated above visitors, visitor numbers had no impact on the orangutans' behavior. However, when the orangutans were housed in an enclosure positioned at visitor eye level, as visitor numbers increased so did alert and begging behaviors directed towards visitors. From this, the authors concluded that housing the orangutans in elevated positions above visitors may have provided the orangutans with a greater sense of security or dominance. Thus, it appears that birds that spent the majority of their time in the canopy may have had a greater sense of security than the birds that spent the majority of their time at ground level, due in part to their ability to position themselves elevated above visitors.

Vegetation use and range size were also examined as outcomes that might be associated with increased visitor levels. Two species (hottentot teal and sunbittern) displayed an increased use of vegetation cover during periods of high visitor numbers (Table 5). Additionally, in five species (African openbill, blue-breasted kingfisher, great curassow, hottentot teal and the scarlet ibis population in section A of the aviary), decreases in range size of at least 10 percent were observed during periods of high visitor numbers (Table 6). Four of these species (African openbill, blue-breasted kingfisher, great curassow, and scarlet ibis) did not show movement away from the visitor pathway as visitor number/noise levels increased. Thus, these reductions in range size do not necessarily appear to be focused around the path where visitors were present, but instead, may be a decrease in the overall space that the birds were using, regardless of their position in the enclosure. Previous studies have recorded percent of time spent out of sight (Collins \& Marples, 2016; Downes, 2012), or degree of visibility of animals (Mun et al., 2013; Schäfer, 2014; Sherwen et al., 2014), as potential components of negative visitor effects. Similarly, reductions in range sizes or partial visibility achieved in vegetation cover may be alternative responses used to maintain control over how the animals interact with, or the extent to which they interact with, visitors in their environment as a potentially disruptive stimulus.

\section{Welfare Implications: Behavior}

Our results provided no evidence that visitor period (periods of low or high visitor numbers) significantly influenced the performance of stress (aggression, pacing) or critical behaviors (feeding and drinking, nesting, resting). Thus, there was no evidence to indicate that the birds were experiencing increasing stress levels or interference with their critical behaviors as a result of high visitor numbers. It should be noted, species that had a greater number of individuals in their population (e.g., scarlet ibis with a population of 39 birds, as compared to the blue-breasted kingfisher with only one bird) may have a disproportionate effect on the results. However, the performance of stress related behaviors remained low throughout the duration of the study across all species. Aggression behavior made up 0.40 percent of total behavior recorded, and pacing made up 0.35 percent of total behavior. These low levels of stress related behaviors may have made the birds less susceptible to visitor effects overall. Regardless, working within the constraints of the current study, the results provided no outward evidence that suggests that the welfare of the birds housed in the Main Free-flight Aviary was negatively impacted by increasing visitor numbers. When considering this conclusion in conjunction with the birds' use of their enclosure, it appears that the manner in which the birds were using the space within the aviary may be responsible for minimizing effects of high visitor numbers, explaining the low level of behavioral changes observed. 


\section{Potential Coping Mechanisms: Bringing Together Behavior and Enclosure Use}

We propose that the changes in enclosure use observed in several species - movement away from the visitor pathway, increases in vegetation use, and decreases in range sizes - may in themselves be mechanisms used to cope with increasing visitor numbers and noise levels. The species that showed these responses may still find high numbers of visitors to be aversive or disruptive. However, the ways in which they altered their enclosure use under periods of increased visitor numbers and noise levels appears to allow for multiple means in which the birds could use the control and freedom of movement provided to them in a barrier-free enclosure to distance themselves from visitor presence. These measures provide insight into the mechanisms by which animals may utilize these properties of free-range enclosures to minimize visitor effects (Anderson et al., 2002; Choo et al., 2011; Collins et al., 2017; Collins \& Marples, 2016; Fernandez et al., 2009; Hosey, 2000; Rose et al., 2018; Woolway \& Goodenough, 2017). It is proposed that these responses may keep stress levels of the birds low, in respect to visitor numbers and noise levels, explaining the apparent lack of influence of visitor numbers on behavior. Thus, these birds may have adapted to visitor presence in the aviary, at least in part, through the use of their environment as a means of coping with increasing visitor levels. Factors such as habituation or a positive perception of visitors due to a positive relationship with keepers should also be considered as playing a role in minimizing the behavioral responses observed (Choo et al., 2011; Collins et al., 2017; Woolway \& Goodenough, 2017). These factors may be particularly relevant for species that showed no apparent changes in their movement away from the visitor pathway, use of vegetation cover, or changes in range size as visitor numbers varied (African spoonbill, black-bellied whistling duck, boat-billed heron, buffbanded rail, Inca tern, mandarin duck, red-legged seriema, spotted whistling duck, violet turaco and the scarlet ibis housed in section B of the aviary). Habituation and/or a positive perception of humans due to keeper relationships may explain in-part the apparent lack of visitor effects observed in these species.

\section{Limitations and Future Directions}

Firstly, the weak correlations between the distance of the birds from the visitor pathway and visitor numbers/noise levels must be considered. Although the trends indicate a relationship between visitor presence and enclosure use, they also indicate that there is more variation that may be accounted for through variables that were not measured. For instance, individual temperament, the animal's size, if the animal is a prey species, and previous exposure to humans, are all factors that have been noted as potentially impacting how an animal responds to increasing visitor levels (Fernandez et al., 2009; Stoinski et al., 2012; Woolway \& Goodenough, 2017). As well, due to the presence of the observers, a 'no visitor period' could not be achieved. As such, the possibility must be considered that, for some species, any humans within the enclosure may have been enough to induce a visitor effect, potentially impacting their enclosure use and behaviors throughout the duration of the study. The 12-day sampling period and the 30 min delay between consecutive samples of individual birds should also be considered as limitations, as the study may not have captured the full extent of bird behavior, enclosure use, and visitor and environmental variability. These factors, as well as the small sample sizes available for many of the species at Zoo Tampa at Lowry Park, should be taken into account when extrapolating the results of this study to other zoos or institutions. Overgeneralization of visitor effects should be avoided. Instead, studies such as this add to the collective information surrounding the topic, providing insight that may be helpful when informing future housing decisions, but must still be considered within the context of each unique scenario. As such, research that focuses on the topics discussed above, which could not be accommodated in the current study, is critical.

\section{The Benefits of Incorporating GIS}

Throughout data collection, storage and analysis, GIS proved to be a helpful tool. GIS has been used twice previously to examine visitor effects in zoos (Bonnie et al., 2016; Smith, 2014). In both cases, 
digital maps were used to track the three-dimensional locations of individual primates (gorillas and orangutans) comparing the vertical and horizontal distance of the animals from the visitor viewing areas, to the number of visitors surrounding the enclosure. In the current study, we found that GIS allowed for the easy collection of precise 3D location data, in an environment where equally detailed quadrant sampling would not have been possible due to the size and complexity of the aviary. GIS as a tool to study enclosure use in zoos, apart from the context of visitor effects, is explored further in an accompanying paper (Blanchett et al., in prep). In that manuscript, the same data set described here is used to map and compare the grouping patterns of species distribution, habitat use and range overlap in the community of birds housed in the Main Free-flight Aviary at Zoo Tampa at Lowry Park.

\section{Conclusion}

The purpose of this study was to examine how the enclosure use of birds housed in a mixed species free-range environment varied under differing levels of visitor numbers and noise levels. Several changes in the birds' use of their enclosure were observed during periods of high visitor numbers, including; movement further away from the visitor path, decreased range size, and increased use of ground vegetation cover. However, the lack of substantial changes in critical behaviors and stress related behaviors observed appears to indicate little to no negative welfare consequences for the birds under such circumstances. As such, it is suggested that changes in enclosure use exhibited by some of the birds, worked as a coping mechanism to manage and mitigate potentially stressful visitor effects. These findings support the theory that the freedom of movement, allowance for retreat spaces, and greater degree of control allowed for in free-range environments, decreases the potential for negative welfare consequences from visitor effects. Information on birds living in free-range enclosures serves to add to the limited information currently available concerning visitor effects on birds. Understanding more about these responses in the context of visitor effects is crucial for striking a balance with habitats that both the animals, as well as the visitors, can enjoy and benefit from to the greatest extent.

\section{Ethical Approval}

Ethical approval for the current study was obtained through the University of Guelph Animal Care Services (approval number \# 3759).

\section{Acknowledgements}

We would like to acknowledge that an associated report using the same data set is being prepared for publication at the current time.

This research was supported in part by the Ontario Graduate Scholarship and the Graduate Research Tuition Scholarship provided through the University of Guelph. We would like to acknowledge the keepers and staff at the Main Free-flight Aviary, Zoo Tampa at Lowry Park, for their invaluable insight into the birds. As well, many thanks to the Vice President of Medical Sciences and Senior Veterinarian at Zoo Tampa at Lowry Park, Dr. Ray Ball, for his support facilitating this research. As well, thanks to Dr. Ian Duncan and Dr. Andy Robinson for their contributions to the research. We are also very grateful to Shining Wang for her assistance in data collection, and Dave Parkinson and Bethany Vlaming for the provisioning of appendix photos. We thank Daryl Blanchett and Adam Bonnycastle for their aid in methods development and Dr. Michelle Edwards for her aid with the development of statistical analysis procedures.

\section{References}

Anderson, U. S., Benne, M., Bloomsmith, M. A., \& Maple, T. L. (2002). Retreat space and human visitor density moderate undesirable behavior in petting zoo animals. Journal of Applied Animal Welfare Science, 5, 125137. 
Blanchett, M., Finegan, E., Bonnycastle, A., \& Atkinson, J. Using GIS to examine space selection and enclosure use by birds within a mixed species free-ranging zoo environment. In preparation.

Bonnie, K. E., Ang, M. Y. L., \& Ross, S. R. (2016). Effects of crowd size on exhibit use by and behavior of chimpanzees (Pan troglodytes) and Western lowland gorillas (Gorilla gorilla) at a zoo. Applied Animal Behaviour Science, 178, 102-110.

Carlstead, K., \& Shepherdson, D. (2000). Alleviating stress in zoo animals with environmental enrichment. In G.P. Moberg, \& J. A. Mench (Eds.), The biology of animal stress: Basic principles and implications for animal welfare (pp. 337-354). New York: CABI Publishing.

Choo, Y., Todd, P. A., \& Li, D. (2011). Visitor effects on zoo orangutans in two novel, naturalistic enclosures. Applied Animal Behaviour Science, 133, 78-86.

Claxton, A. M. (2011). The potential of the human-animal relationship as an environmental enrichment for the welfare of zoo-housed animals. Applied Animal Behaviour Science, 133, 1-10.

Clayton, S., Fraser, J., \& Saunders, C. D. (2009). Zoo experiences: Conversations, connections, and concern for animals. Zoo Biology, 28, 377-397.

Collins, C., Corkery, I., Haigh, A., McKeown, S., Quirke, T., \& O’Riordan, R. (2017). The effects of environmental and visitor variables on the behavior of free-ranging ring-tailed lemurs (Lemur catta) in captivity. Zoo Biology, 36, 250-260.

Collins, C. K., \& Marples, N. M. (2015). Zoo playgrounds: A source of enrichment or stress for a group of nearby cockatoos? A case study. Journal of Applied Animal Welfare Science, 18, 375-387.

Collins, C. K., \& Marples, N. M. (2016). The effects of zoo visitors on a group of Western lowland gorillas Gorilla gorilla before and after the birth of an infant at Dublin Zoo. International Zoo Yearbook, 50, $183-192$.

Davey, G. (2007). Visitors' effects on the welfare of animals in the zoo: A review. Journal of Applied Animal Welfare Science, 10, 169-183.

de Azevedo, C. S., Figueiredo Lima, M. F., da Silva, V. C. A., Young, R. J., \& Rodrigues, M. (2012). Visitor influence on the behavior of captive greater rheas (Rhea americana, Rheidae Aves). Journal of Applied Animal Welfare Science, 15, 113-125.

de Vere, A. J. (2018). Visitor effects on a zoo population of California sea lions (Zalophus californianus) and harbor seals (Phoca vitulina). Zoo Biology, 37, 162-170.

Downes, K. (2012). Is there a visitor effect on behaviour and enclosure use of mixed bird species in a zoo enclosure? The Plymouth Student Scientist, 5, 38-60.

Fernandez, E. J., Tamborski, M. A., Pickens, S. R., \& Timberlake, W. (2009). Animal-visitor interactions in the modern zoo: Conflicts and interventions. Applied Animal Behaviour Science, 120, 1-8.

Hosey, G. (2000). Zoo animals and their human audiences: What is the Visitors Effect? Animal Welfare, 9, $343-357$.

Hosey, G. (2008). A preliminary model of human-animal relationships in the zoo. Applied Animal Behaviour Science, 109, 105-127.

Hosey, G. (2013). Hediger revisited: How do zoo animals see us? Journal of Applied Animal Welfare Science, 16, 338-359.

Hosey, G., \& Melfi, V. (2014). Are we ignoring neutral and negative human-animal relationships in zoos? Zoo Biology, 34, 1-8.

IUCN Red List. (2018). IUCN Red List of Threatened Species ${ }^{\text {TM }}$. https://www.iucnredlist.org/

Kyngdon, D. J., Minot, E. O., \& Stafford, K. J. (2003). Behavioural responses of captive common dolphins Delphinus delphis to a "Swim-with-Dolphin" programme. Applied Animal Behaviour Science, 81, 163170 .

Larsen, M. J., Sherwen, S. L., \& Rault, J. L. (2014). Number of nearby visitors and noise level affect vigilance in captive koalas. Applied Animal Behaviour Science, 154, 76-82.

Martin, P., \& Bateson, P. (2007). Measuring behaviour: An introductory guide. Cambridge, UK: Cambridge University Press.

Morgan, K. N., \& Tromborg, C. T. (2007). Sources of stress in captivity. Applied Animal Behaviour Science, 102, 262-302.

Mun, J. S. C., Kabilan, B., Alagappasamy, S., \& Guha, B. (2013). Benefits of naturalistic free-ranging primate displays and implications for increased human-primate interactions. Anthrozoos, 26, 13-26.

Quadros, S., Goulart, V. D. L., Passos, L., Vecci, M. A. M., \& Young, R. J. (2014). Zoo visitor effect on mammal behaviour: Does noise matter? Applied Animal Behaviour Science, 156, 78-84.

Reade, L. S., \& Waran, N. K. (1996). The modern zoo: How do people perceive zoo animals? Applied Animal Behaviour Science, 47, 109-118. 
Rose, P. E., Brereton, J. E., \& Croft, D. P. (2018). Measuring welfare in captive flamingos: Activity patterns and exhibit usage in zoo-housed birds. Applied Animal Behaviour Science, 205, 115-125.

Schäfer, F. (2014). To see or not to see: Animal-visibility in Apenheul Primate Park. International Zoo News, 61, 520.

Sherwen, S. L., Harvey, T. J., Magrath, M. J. L., Butler, K. L., Fanson, K. V., \& Hemsworth, P. H. (2015). Effects of visual contact with zoo visitors on black-capped capuchin welfare. Applied Animal Behaviour Science, $167,65-73$.

Sherwen, S. L., Hemsworth, P. H., Butler, K. L., Fanson, K. V., \& Magrath, M. J. L. (2015). Impacts of visitor number on kangaroos housed in free-range exhibits. Zoo Biology, 34, 287-295.

Sherwen, S. L., Magrath, M. J. L., Butler, K. L., \& Hemsworth, P. H. (2015). Little penguins, Eudyptula minor, show increased avoidance, aggression and vigilance in response to zoo visitors. Applied Animal Behaviour Science, 168, 71-76.

Sherwen, S. L., Magrath, M. J. L., Butler, K. L., Phillips, C. J. C., \& Hemsworth, P. H. (2014). A multi-enclosure study investigating the behavioural response of meerkats to zoo visitors. Applied Animal Behaviour Science, 156, 70-77.

Smith, Z. J. (2014). Mapping the spatial movements, behaviors, and interactions of captive orangutans using terrestrial laser scanning and GIS (Master's thesis). Retrieved from https://scholarcommons.usf.edu/

Stoinski, T. S., Jaicks, H. F., \& Drayton, L. A. (2012). Visitor effects on the behavior of captive western lowland gorillas: The importance of individual differences in examining welfare. Zoo Biology, 31, 586-599.

Thicks, S. F. (2008). Is there a visitor effect on Abyssinian ground hornbills (Bucorvus abyssinicus), Papuan wreathed hornbills (Aceros plicatus), wrinkled hornbills (Aceros corrugatus) and Toco toucans (Ramphastos toco) in a captive zoo environment? The Plymouth Student Scientist, 1, 30-55.

Wenger, K. F. (1984). Forestry handbook (Vol. 84, No. 1). New Jersey, USA: John Wiley \& Sons.

Whitham, J. C., \& Wielebnowski, N. (2013). New directions for zoo animal welfare science. Applied Animal Behaviour Science, 147, 247-260.

Woolway, E. E., \& Goodenough, A. E. (2017). Effects of visitor numbers on captive European red squirrels (Sciurus vulgaris) and impacts on visitor experience. Zoo Biology, 36, 112-119. 


\section{Appendix}

Below is a visual species guide, for the 24 bird species included in the current study, housed in the Main Free-flight Aviary at Zoo Tampa at Lowry Park, FL. Photos provided courtesy of Dave Parkinson $^{1}$ and Bethany Vlaming ${ }^{2}$.

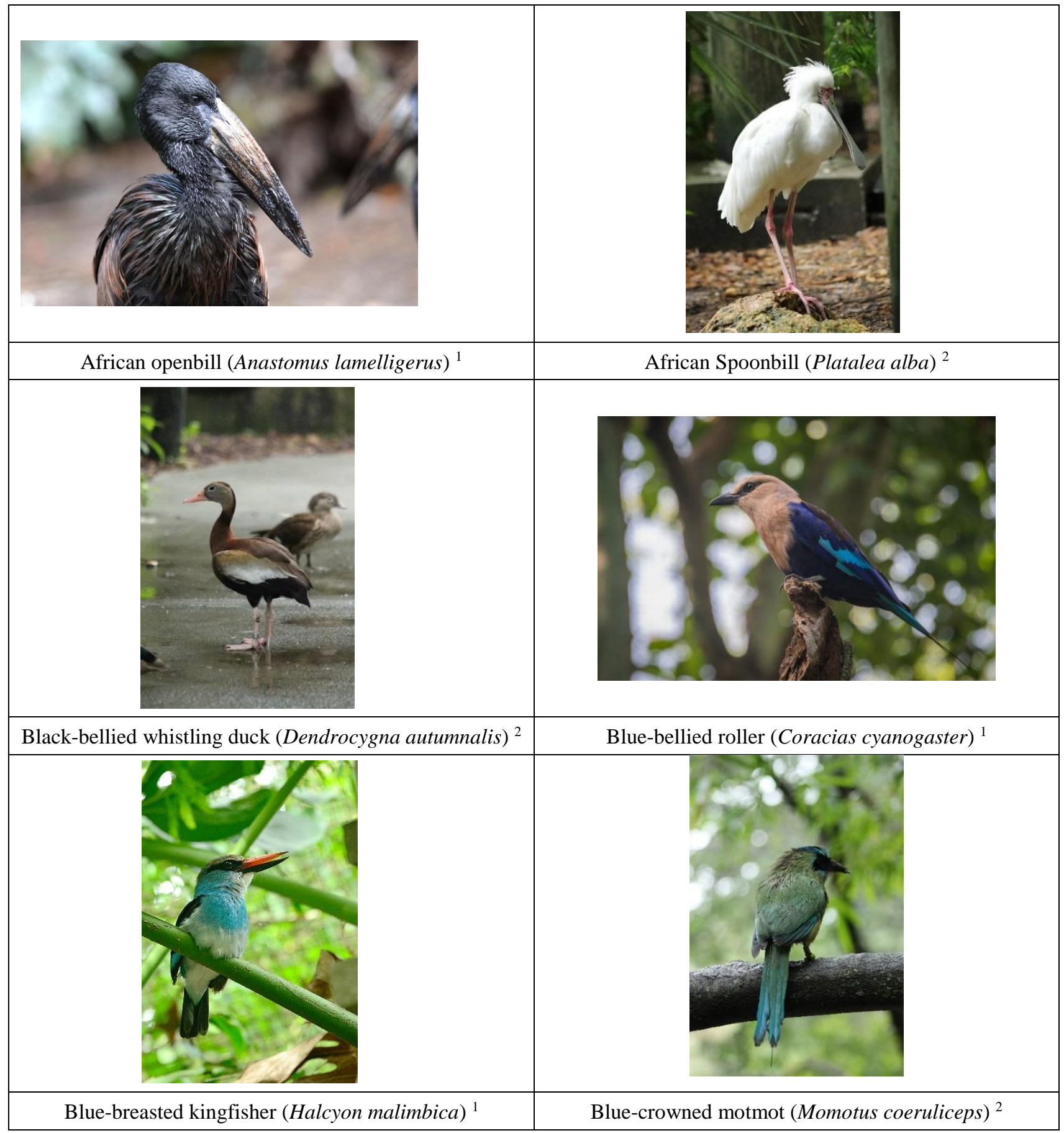




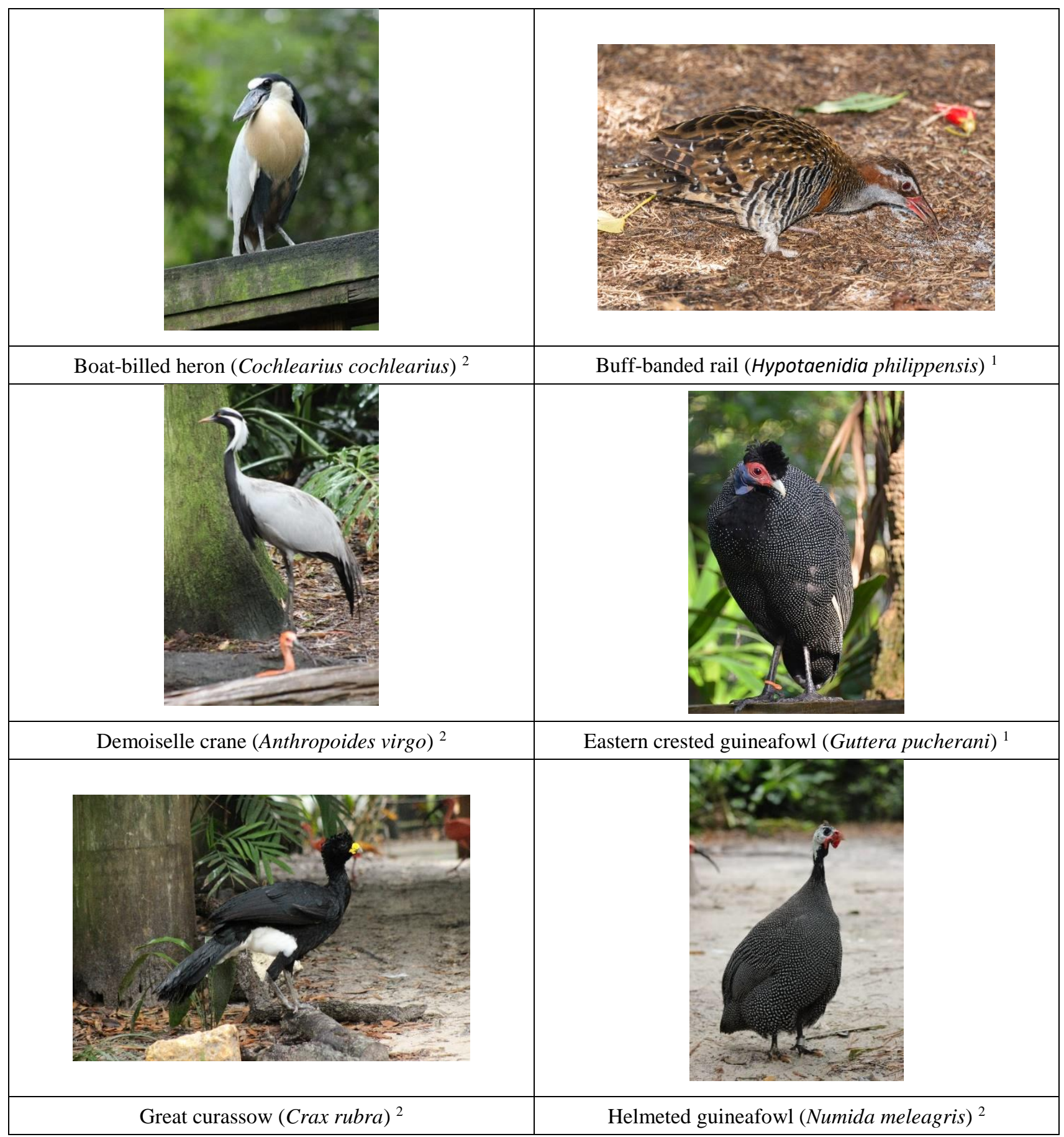




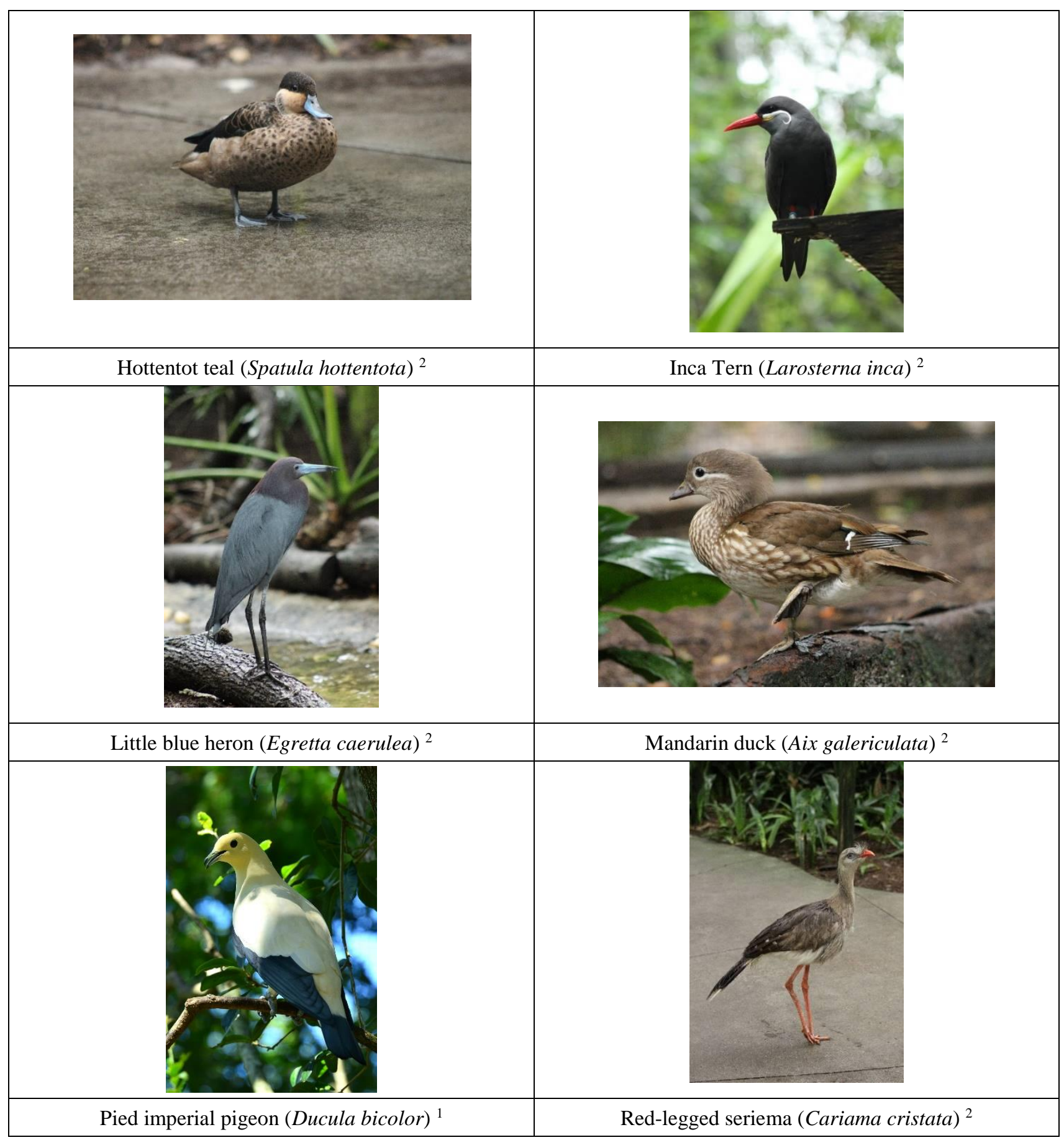




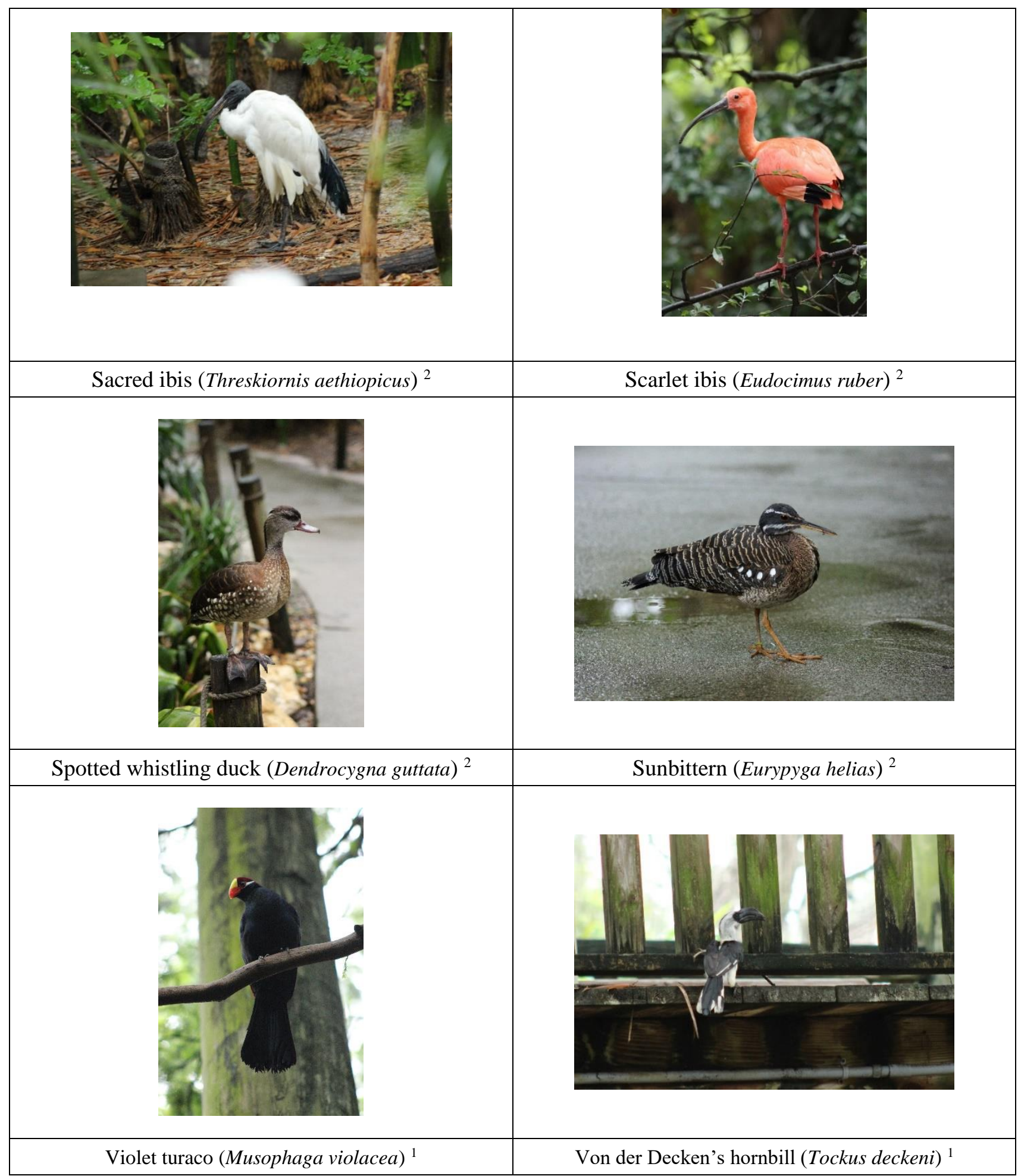

